\title{
Small Gas Turbine Combustor Experimental Study-Compliant Metal/Ceramic Liner and Performance Evaluation
}

(NASA-TM-87304) SMALL GAS TUREINE COMBUSTOR

EXP ER IMENTAL STUDY: COMPLIANT. METAL/CERAMIC

I.INER AND PERFOKMANCE EVALUATION (NASA)

$16 \mathrm{p}$

CSCL 21E

$63 / 07 \quad$ Onclas

Waldo A. Acosta

Propulsion Directorate

U.S. Army Aviation Research and Technology Activity-AVSCOM

Lewis Research Center

Cleveland, Ohio

and

Carl T. Norgren

Lewis Research Center

Cleveland, Ohio

Prepared for the

22nd Joint Propulsion Conference

cosponsored by the AIAA, ASME, SAE, and ASEE

Huntsville, Alabama, June 16-18, 1986

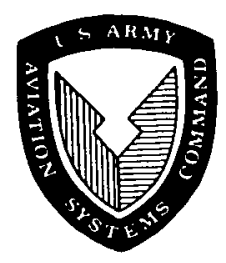


SMALL GAS TURBINE COMBUSTOR EXPERIMENTAL STUDY - COMPLIANT METAL/CERAMIC LINER

\section{AND PERFORMANCE EVALUATION}

Waldo A. Acosta

Propulsion Directorate

U.S. Army Aviation Research and Technology Activity - AVSCOM

Lewis Research Center

Cleveland, Ohio

and

Carl T. Norgren

National Aeronautics and Space Administration

Lewis Research Center

Clevel and, Ohio

Abstract

Combustor research relating to the development of fuel efficient small gas turbine engines capable of meeting future commercial and military aviation needs is currently underway at NASA Lewis. As part of this combustor research, a basic reverse-flow combustor has been used to investigate advanced liner wall cooling techniques. Liner temperature, performance, and exhaust emissions of the experi-

mental combustor utilizing compliant metal/ceramic

liners were determined and compared with three pre-

w viously reported combustors that featured: (1) splash film-cooled liner walls; (2) transpiration cooled liner walls; and (3) counter-flow film cooled panels.

\section{Introduction}

Problems unique to small combustors were reviewed during a forum at NASA Lewis conducted by A.D. Little, Inc. 1 The objective was to identify the R\&D effort which must be considered in the 1980 to 1990 time frame to meet the critical needs for small aircraft gas turbines. Combustor liner cooling requirements were the prime concerns. Advancements in gas turbine cycle efficiency and lowered specific fuel consumption are realized by increasing cycle pressure ratios and turbine inlet temperature, and/or implementing either regenerative or recuperative cycles. Combustors operating at these conditions require increased amounts of cooling air. However, additional air is not available due to the larger amounts required to increase turbine inlet temperature and for turbine cooling. The remaining available air is hotter due to increased pressure ratio and/or regenerative cycle operation. This loss in heat sink capability is particularly critical in the small combustor system due to the inherent high surface-to-volume ratio. Consequently, improvement in coolant utilization is mandatory to achieve higher cycle efficiencies.

In recent years there has been a rapid growth in research and development aimed at introducing high temperature ceramic materials and/or ceramic composites into gas turbine engines which require little or no coolant and minimize or eliminate the need for strategic high temperature metal materials. Previous experimental research has shown that ceramics are prone to stress failures induced by thermal shock. If, however, a ceramic is sprayed on a plyable substrate, a major improvement in thermal cyclic fatigue results. 2 A joint NASA/Army program was initiated to develop new technology for applying the ceramic matrix concept to combustor liners. This program is aimed at identifying and evaluating promising concepts. The experimental studies were specifically formulated to:

(1) Investigate design and off-design parameters which determine stable long life for compliant ceramic combustor liners.

(2) Investigate the aerothermal performance impact of replacing current technology film cooled louver liners with uncooled ceramics.

(3) Identify high potential advanced compliant ceramic liner concepts.

For this study, a simplified compliant ceramic liner concept was selected to facilitate implementation into research hardware. The design and fabrication of the combustor aerothermodynamics was patterned after an existing NASA reverse-flow $\mathrm{fi} 1 \mathrm{~m}$ cooled design. 3 To maintain internal flow dynamics, the physical geometry, air-entry distribution, and combustor pressure drop across the liner were similar. The conventional existing splash film-cooled wall was designed using a onedimensional computational scheme assuming a steadystate heat flux balance between the heat gained by the wall and the heat lost. Conduction within the wall and radiation interchange between the hot walls were considered negligible.

Documentation of liner cooling effectiveness, combustion efficiency, and emission index levels over a range of simulated flight conditions of a 16:1 compression pressure ratio gas turbine engine with Jet A fuel was obtained.

\section{Apparatus}

Test Facility

The combustor was mounted in duct $A$ of the test facility CE9B (Fig. 1) located in the Engine Research Building (building 5) at Lewis. Tests were conducted with inlet-air pressure ranging up to $16 \mathrm{~atm}$ with the air indirectly heated to about a temperature of $717 \mathrm{~K}\left(835^{\circ} \mathrm{F}\right)$. The temperature of the air was automatically controlled by mixing the heated air with varying amounts of cold by-pass air. Airflow through the heat exchanger and by-pass flow system and the total pressure of the combustor were regulated by remotely controlled valves. 
Combustors

The reverse flow combustor used in this investigation was a full scale experimental design. The design was based on versatility so that the interchanging of fuel injectors and the modification or replacement of the swirlers, faceplate, and liner could be readily accomplished. The airflow distribution and hole sizing of the liner were based on 36 primary holes and 36 dilution holes. In this investigation four combustors with similar internal aerothermal design, but different liner wall cooling schemes are compared. The cooling configurations were: (1) splash-film (SF); (2) a pseudotranspiration liner "LAMILLOY"* (TRANS); (3) a counter-flow film-cooled liner (CFFC); and (4) a compliant metal/ceramic liner (CMC). Design details and performance of the referenced SF and TRANS designs are presented in Ref. 5 , the CFFC is presented in Ref. 6. A summary of the design of the CMC liner relevant to the present investigation follows.

Compliant metal/ceramic liner. The research objective was to investigate advanced combustor liner concepts capable of withstanding temperature environments associated with temperature levels of $1922 \mathrm{~K}\left(3000^{\circ} \mathrm{F}\right)$, while providing improved cyclic durability with iittle or no coolant air. The experimental study was performed under $h$ igh pressure and temperature environments simulating those encountered in combustors operating under advanced cycle conditions. Since structural parameters relating to size, curvature, stresses, etc.; are difficult to scale, full scale combustor hardware was utilized. Consequently, to enable a more direct comparison with metallic liners, the geometric configuration used in the previously reported liner-cooling study of Ref. 6 was also used.

The CMC liner concept was evolved from recent studies as discussed in Refs. 2 and 7 . These studies outlined the application of ceramics to combustor. 1 iners by means of plasma spraying an yttria stabilized zirconia (YSZ) on a compliant nickel alloy substrate. This compliant metal substrate was designed to yield at relatively low levels of stress, thereby absorbing the differential expansion which develops between the metal and the ceramic as the material is heated. The compliant metal substrate was made from randomily oriented fibers which are sintered for strength. A wide range of physical and mechanical properties are obtainable by controlling product alloy, fiber diameter, porosity (or density), and sintering conditions. Fiber diameter influences both insulating characteristics and oxidation resistance of the compliant metal substrate.

In the reported studies the ceramic thickness, material type, and yttria percentages were varied as well. as the compliant metallic type, density, and material. In the study a NiCrAly bond coat between the ceramic and compliant metal substrate was used for the 8.64 by $9.90 \mathrm{~cm}$ test pads. The test pad was cycled at a simulated flame temperature of $2170 \mathrm{~K}\left(3445^{\circ} \mathrm{F}\right)$ for a period of $2 \mathrm{~min}$ with a backside coolant temperature of $493 \mathrm{~K}\left(427^{\circ} \mathrm{F}\right)$. The results of these tests indicated that a compliant metallic structure coated with a sprayed on ceramic coating could withstand the stresses induced in the combustor environment. In particular the results suggested the superiority of a system composed of a BRUNSBOND* Hosk ins -875 compliant pad approximately $0.25 \mathrm{~cm}$ thick and 35 percent dense, coupled with a NiCrAlY bond coat and a 8 percent YSZ ceramic top coat approximately $0.19 \mathrm{~cm}$ thick. 2

In order to investigate the feasibility of applying this concept to an experimental combustor configuration, Brunswick Technetics was contracted to determine if the compliant metallic material and ceramic coating could be fabricated in a size and shape consistent with the existing reverse-flow small combustor configuration. As a result, the actual combustion and dilution sections were simulated by appropriate cylindrical sections. Brunswick Technetics under NASA contract fabricated two cylindrical shells: one, $38.74 \mathrm{~cm}$, and the other $28.40 \mathrm{~cm}$ in diameter. The wall penetrations for the primary and dilution holes were identical to the NASA reverse-flow combustor configuration. 3 The compliant metal shell was $0.1524 \mathrm{~cm}$ Hoskins 875,35 percent dense, brazed to a Hastelloy $X$ metal substrate on one side and coated with an YSZ type ceramic (a mixture designated as GJ-1 propietary with Brunswick) on the other side. Although the liner was coated in one continuous spraying process the composition of the ceramic coating was altered about half way through the spraying process. The change in composition was intended to minimize internal thermodynamics stresses within the ceramic coating. Figure 2 shows a cross-sectional view of the CMC liner concept.

In order to expedite the experimental evaluation an existing NASA faceplate and turn section were used to complete the configuration as shown in Fig. 3. In this first order approach it was also elected to limit the combustor outlet temperature level to values 200 to $400 \mathrm{~K}$.higher than current practice rather than strive for the original $1922 \mathrm{~K}\left(3000^{\circ} \mathrm{F}\right)$. goal. This allowed the major simplification of using only backside convective. cooling which was provided by the passage between the combustor wall and casing. 0xidation of the bond coat is known to occur at temperatures above $1228 \mathrm{~K}\left(1750^{\circ} \mathrm{F}\right)$ and lead to failure of the ceramic due to a complex interaction.? Therefore, in. order not to exceed the design temperature level of $1228 \mathrm{~K}\left(1750^{\circ} \mathrm{F}\right)$ at the bond coat, the outlet temperature was limited to approximately $1789 \mathrm{~K}$ $\left(2760^{\circ} \mathrm{F}\right)$.

\section{Instrumentation}

The combustor instrumentation stations are shown in Fig: 4. Five total pressure probes, two static pressure taps, and four Chromel-Alumel thermocouples are located at station 2 to measure the inlet pressure and temperature. At station 3, a series of 18 total pressure probes are installed to determine the inlet-air profile and to determine the extent of any flow disturbance behind the struts which support the centerbody diffuser. At station 4 , six pitot-static probes are positioned in the cold-air passages between the combustor 1 iner and combustor housing to determine passage velocity and distribution. At station 5, outlet temperature and pressure measurements are obtained by means of a rotating

\footnotetext{
*Trademark.
} 
probe. The probe contains three rakes spaced $120^{\circ}$ apart, a five-position radial rake containing PT-PT 13 percent Rd thermocouples, a five-position total pressure rake, and a water cooled gas sampling rake. A $360^{\circ}$ travel with sampling at $10^{\circ}$ increments was used for this program.

\section{Procedure}

\section{Test Conditions}

The experimental reverse flow combustor was operated at test conditions based on a gas-turbine engine cycle with a compressor pressure ratio of 16. A tabulation of the test conditions used in this study is given in Table 1.

Data were obtained at combustor inlet conditions simulating sea level take-off (SLTO), and high altitude cruise. A series of thermal cycles were run at conditions simulating SLTO to study the durability. of the CMC concept. Figure 5 shows the test sequence followed and the amount of time that the combustor operated at the specified exit temperature. Each cycle consisted of a start, test condition set and shut-down. Starting was initiated at reduced temperature, pressure, and airflow. The system was then quickly set to the desired test conditions of pressure, temperature, air, and fuel flow, and maintained for a selected period of time after which the flame was extinguished. The combustor was allowed to cool to ambient temperature after which the cycle was repeated. Simulated flight data were obtained at fuel-air ratios up to approximately 0.030 . The simulated combustor test conditions were based on a reference velocity of $5.49 \mathrm{~m} / \mathrm{sec}(18 \mathrm{ft} / \mathrm{sec})$. The reference velocity quoted was based on unidirectional total mass flow and the maximum cross-sectional area of the housing prior to the reverse turn (Fig. 4).

The test program was conducted using Jet-A fuel with 18 simplex pressure-atomizing fuel injectors with a flow number of 4.8 .

Emission Measurements

Exhaust gas samples were obtained according to the recommended procedures in Refs. 8 and 9. Exhaust gases were withdrawn through the water cooled rotating probe mounted approximately in the stator plane and in the center of the exhaust duct at station 5 ( $\mathrm{Fig} .4$ ). The gas sample temperature was held at approximately $423 \mathrm{~K}\left(302^{\circ} \mathrm{F}\right)$ in the electrically heated sampling line. Most of the gas sample entered the analyzer oven, while the excess sample was bypassed to the exhaust system. To prevent fuel accumulation in the sample line, a nitrogen purge was used before and during combustor ignition.

After passing through the analyzer oven the gas sample was divided into three parts, and each part was analyzed. Concentrations of oxides of nitrogen, carbon monoxide and carbon dioxide, and hydrocarbons were measured by the chemiluminescence, nondispersed-infrared, and flame ionization methods, respectivelv. Details of the gas analysis system are presented in Ref. 3.

\section{Results and Discussion}

A combustor featuring an advanced liner cooling technique known as the compliant metal/ceramic
(CMC) combustor liner was operated at conditions typical of a 16:1 pressure ratio turbine engine. Liner temperature, combustion efficiency, and exhaust emissions are presented for simulated flight conditions. Comparison with a counter-flow film-cooled (CFFC) combustor, a conventional splash film-cooled (SF) liner, and a simulated transpiration cooled (TRANS) combustor (Lamilloy) are also included.

\section{Liner Temperature}

Liner wall temperature. The liner temperature data as a function of fuel air ratio for the sea level take-off (SLTO) condition is shown in Fig. 6. The data presented are for two thermocouples located on the surface of the inner and outer liner 3.81 and $8.89 \mathrm{~cm}$ from the faceplate, respectively. Both thermocouples were positioned in-between a different pair of nozzles. Each thermocouple measurement represents the maximum temperatures measured for each liner. The highest temperature levels were measured on the inner liner with the maximum indication of $1122 \mathrm{~K}\left(1560^{\circ} \mathrm{F}\right)$. The only cooling provided to the compliant metal/ceramic liner was backside convection.

Velocity probes located at station 4 (Fig. 4) measured air velocity and distribution in the coldair passages between the combustor liners and the combustor housing. Average air velocities of 20 and $40 \mathrm{~m} / \mathrm{s}$ were measured for the inner and outer cold-air passages, respectively. The difference in air velocity results in a reduction of the convective heat transfer for the inner liner. In addition, the heat flux with in the combustor varies due to the flame stabilization and combustion process. The resultant liner temperature is an indication of the compliant layer ceramic interface temperature. As previously mentioned an arbitrary temperature level of $1228 \mathrm{~K}\left(1750^{\circ} \mathrm{F}\right)$ was selected as a goal to minimize oxidation of the bond interface between the compliant layer and the ceramic. Measured liner surface temperatures used to inferentially calculate interface temperatures indicated that this leve? was not exceeded.

Liner cooling reduction. The reduction in liner coolant for the CMC configuration is shown in Fig. 7 and compared with the TRANS and CFFC configurations using as a reference the SF configuration. As shown, the CFFC and TRANS configurations used from 40 to 50 percent less air than the SF configuration and the liner temperatures were reduced by 12 percent. The CMC 1 iner coolant flow was reduced by 80 percent and the liner temperature was reduced by 13 percent ( 3.2 percent of the total air flow went through the annulus around the fuel injectors and was considered as coolant flow). This comparison is for the cylindrical part of the combustor liner since it is where the CMC was used.

As shown, the TRANS, CFFC, and CMC configurations had similar reductions in liner temperature, but the CMC liner provided exhaust temperatures $167 \mathrm{~K}\left(300^{\circ} \mathrm{F}\right)$ hotter than current practice. Although the CMC liner had similar reductions in liner temperature compared to the advanced metallic techniques, the most significant improvements are the reduction of liner coolant flow and the increase in turbine inlet temperature. The reduc$t$ ion of liner coolant flow frees air that $c$ an be used to increase the coolant flow to the turbine allowing the turbine operate at the higher turbine 
inilet temperatures of advanced engine cycles. In addition, increasing the turbine inlet temperature could increase the cycle efficiency of the gas turbine engine.

\section{Liner Durability}

A series of thermal cyclic tests were imposed on the CMC liner to study its durability. Eight hours of operation were logged at a simulated 16:1 pressure ratio condition at outlet temperatures of $1561 \mathrm{~K}\left(2350^{\circ} \mathrm{F}\right)$. An additional 2 hours of operation were obtained at an elevated temperature of $1718 \mathrm{~K}\left(2630^{\circ} \mathrm{F}\right)$. Figure $8(\mathrm{a})$ shows the condition of the CMC liners after the first hour of operation at an outlet temperature of $1561 \mathrm{~K}\left(2350^{\circ} \mathrm{F}\right)$. The inner liner encountered some spallation of the ceramic as a result of stresses. As previously indicated, the ceramic composition was altered during the spraying process. The spallation of the ceramic, as will be shown later, occurred at the boundary created when the ceramic composition was changed. The relatively low tensile strength of ceramic materials may have caused the spallation of the ceramic since the inner liner was subjected to tensile stresses. The outer liner, which is subjected to compression stresses, however, did not show any sign of spallation.

The condition of the liners after thermal cycling was completed is shown in Fig. 8(b). The condition of the CMC 1 iner was also observed after the first cycle. At this time a slight separation of the ceramic layers on the inner liner was observed. An area approximately $6.5 \mathrm{~cm}\left(1 \mathrm{in} .^{2}\right)$ was affected by spallation. The remaining ceramic coating appeared to be intact; consequently, the rig was reassembled and the testing continued. Sometime after the first cycle of operation (Fig. 8(a)) and the end of the testing program a second spallation of the ceramic occurred on the inner liner. After the spallation of the top ceramic layer, the remaining ceramic layer did not provide the required thermal barrier protection to avoid oxidation of the compliant layer as shown in the figure. The outer liner showed very good short term durability with no spallation.

After the tests were completed the liners were cut and a series of photomicrographs of the cross section were taken. Figure $9(a)$ shows a cross section of the outer liner. It is evident from this figure that the change in ceramic composition created two distinct layers. "Mudflat" cracks are observed in the top layer, but not in the bottom layer. With the exception of these cracks, the outer liner appearance and performance were unchanged.

A photomicrograph of the inner liner cross section is shown in Fig. 9(b). This figure shows a section where the top ceramic layer spalled off. As indicated earlier, the spallation occurred at the boundary created by the two different ceramic compositions used in the spraying process. The bottom ceramic layer did not separate from the compliant layer, and there was no visible damage to the compliant layer, the metal substrate, or the compliant layer-metal substrate interface at this particular place. There was some damage done to the compliant layer elsewhere, as a result of not enough thermal protection due to ceramic spallation, but there was no damage done to the metal substrate.

\section{Performance}

The combustion efficiency data are presented in Fig. 10 for the compliant metal/ceramic combustor. Data were obtained at combustor inlet conditions simulating SLTO. At this condition, efficiency levels above 99 percent were measured for the SF, CFFC, and CMC configurations over a range of fuel air ratios. Since air entry placement was geometrically identical for the three combustors, the basic internal aerodynamics and recirculation patterns would be expected to be similar. The primary difference between the CMC liner and the others with respect to the primary and secondary zones is the interaction of the coolant flow with the hot gases. These hot gases issuing from the primary zone usually contain high concentrations of carbon monoxide (CO) and unburned hydrocarbons (UC). If these species are cooled by liner cooling air before reactions go to completion, they will appear in the exhaust gases indicating combustion inefficiency. The hot ceramic walls of the CMC liners, being uncooled, did not quench these reactions.

At low fuel air ratios the combustion efficiency remained above 99 percent but started to drop off. The CMC, SF, and CFFC configurations were tested using 18 simplex pressure atomizing injectors. As previously reported the combustion efficiency depends on fuel atomization. 3 The simplex design depends upon the fuel pressure drop across the injector to provide good atomization. However, the fuel flow rate is also determined by this pressure drop. As a result, when fuel pressure is reduced to lower the fuel flow rate, atomization also is reduced.

\section{Emissions}

Currently there are no emission levels required for the small turbojet, but the emission levels are an indication of the effectiveness of the combustion process in relationship to the internal mixing and flow dynamics. Emission index is defined as the grams of pollutant per kilogram of fuel burned. The emission index for the CMC combustor was iess than one for unburned hydrocarbons. The CO emission index of the CMC and CFFC combustors is shown in $\mathrm{Fig}$. 11. The CO emission index of the CMC and CFFC 1 iners was reduced by increasing the fuel air ratio. Higher fuel flow requires higher pressure drop across the simplex pressure atomizer fuel injector producing better atomization and mixing. The effect of reducing the film cooling air is also shown. The CMC liner, with no film cooling air, resulted in lower $\mathrm{CO}$ emission than the CFFC liner.

The oxides of nitrogen ( $\mathrm{NO}_{\mathrm{x}}$ ) emission levels are presented in $\mathrm{Fig} .12$ for inlet conditions representative of sea level take-off and over a range of fuel air ratios. The main difference between the combustors is the way in which each liner was cooled. In the SF configuration, control of the film cooling air is achieved by means of accurately drilled holes to meter the coolant. A protective film of air is produced on the surface by means of a sheet metal annulus. There is no control over the film thickness of the cooling air.

The CFFC and the TRANS configurations managed the cooling air much better than the SF liner. In both cases the heat sink capability of the cooling 
air was used to transfer heat from the liner metal to the cooling air. Resulting in a better distributed $\mathrm{film}$ at a much higher temperature than the SF configuration. The CMC configuration did not have film cooling air.

The $\mathrm{NO}_{\mathrm{x}}$ emission level for the CMC configuration was lower than the SF configuration, but higher than the CFFC and TRANS configurations. The CMC and TRANS liners have similar NOx emission trends with increasing fuel air ratio and both have a minimum interaction of the coolant with the combustion process. The stoichiometry, mixing, and residence time would be expected to be similar yet a higher $\mathrm{NO}_{x}$ level was experienced with the CMC configuration. This increase in $\mathrm{NO}_{x}$ can probably be attributed to a hotter environment during the period in which $\mathrm{NO}_{\mathrm{x}}$ is formed (i.e., the metallic counterpart operates at a lower wall temperature which contributes to a higher heat flux rate). This hotter environment resulted in increased combustion efficiency as noted in the $\mathrm{CO}$ measurement but would also be conducive to increased NO $x$ formation. The CFFC configuration produced the lowest $\mathrm{NO}_{\mathrm{x}}$ level; however, in this case considerable coolant is admitted in the primary zone which resulted in a reduction in overall stoichiometry ( 9 percent for the CFFC configuration as compared to 3.2 percent for the $C M C$ ).

\section{Summary of Results}

1. The use of the basic NASA reverse-flow combustor design to accommodate a compliant metal/ceramic liner was successfully accomplished using existing design procedures and construction techniques.

2. The compliant metal/ceramic liner required 80 percent less coolant, while the counter-flow film-cooled and the transpiration liners required from 40 to 50 percent less coolant as compared to the reference splash film-cooled liner.

3. All three liners experienced almost the same reduction in liner temperature, 12 to 13 percent, but the compliant metal/ceramic liner provided out let temperatures $167 \mathrm{~K}\left(300^{\circ} \mathrm{F}\right)$ hotter than current practice.

4. The compliant metal/ceramic liner concept resulted in an improvement not only with respect to coolant and liner temperature reduction but also in reduction of the nitrogen oxides $\left(\mathrm{NO}_{\mathrm{x}}\right)$ emissions when compared with the splash

film-cooled liner.

5. Test results indicated that the outer liner exhibited very good short-term durability with no indication of spalling. The inner liner did encounter some spallation of the ceramic as a result of stresses within the coating itself.

6. The combustor was capable of providing higher exit temperatures than currently is possible with conventional cooling techniques. Yet, the liner utilized noncritical, low cost materials, and only convective cooling.

\section{Concluding Remarks}

The experiments also indicated research areas for future compliant metal/ceramic development. Current efforts include: (1) grant studies of internal heat transfer coefficients of the compliant layer, (2) contract studies aimed at evolving combustor design criteria, and (3) in-house experiments aimed at identifying and evaluating promising concepts.

A more significant increase in combustor outlet temperature could be obtained by incorporating some sort of cooling to the metal/ceramic interface. Although the compliant layer helped to reduce some of the stresses, improved durability could be obtained for the inner liner by reducing the tensile stresses in the ceramic layer.

The application of fuel efficient, aggressive high temperature cycles to small gas turbine engines are within the realm of current advanced technology as demonstrated by the application compliant metal/ceramic concept to combustor liner design.

\section{References}

1. Demetri, E.P., Topping, R.F., and Wilson, R.P., Ur., "Study of Research and Development

Requirements of Small Gas-Turbine Combustors," Arthur D. Little, Inc., Cambridge, MA, ADL-83381-2, Jan. 1980. (NASA CR-159796)

2. Venkat, R.S. and Roffe, G.:, "Testing of FeltCeramic Materials for Combustor Applications," General Applied Science Labs., Inc., Westburry, NY, Apr. 1983. (NASA CR-168103)

3. Norgren, C.T., and Riddlebaugh, S.M., "Effect of Fuel Injector Type on Performance and Emissions of Reverse-Flow Combustor," NASA TP-1945, 1981 .

4. "Computer Program for the Analysis of Annular Combustors," Volume 1-Calculation Procedures, Northern Research and Engineering Corp., Cambridge, MA, Report 1111-1, Vol. 1, Jan. 1968 (NASA CR-72374).

5. Norgren, C.T., and Riddlebaugh, S.M.,"Small Gas Turbine Combustor Study - Combustor Liner Evaluation," AIAA Paper 83-0337, Jan. 1983.

6. Norgren, C.T., and Riddlebaugh, S.W., "Advanced Liner-Cooling Techniques for Gas Turbine Combustors," AIAA Paper 85-1290, July 1985.

7. Ercegovic, D.B., Walker, C.L., and Norgren, C.T., "Ceramic Composite Liner Material for Gas Turbine Combustors," AIAA Paper 84-0363, Jan. 1984 .

8. "Control of Air Pollution from Aircraft EnginesEmission Standards and Test Procedures for Aircraft," Federal Register, Volume 38, No. 136, Pt. 2, JuTy 17, 1973, pp. 19088-19103.

9. "Procedure for the Continuous Sampling and Measurement of Gaseous Emissions from Aircraft Turbine Engines," SAE ARP-1256A, 0ct. 1980. 
TABLE 1. - REVERSE-FLOW-COMBUSTOR TEST CONDITIONS

\begin{tabular}{|c|c|c|c|c|c|c|c|c|c|c|}
\hline \multirow{2}{*}{$\begin{array}{l}\text { Test } \\
\text { condi- } \\
\text { tion }\end{array}$} & \multicolumn{2}{|c|}{$\begin{array}{l}\text { Total } \\
\text { airflow }\end{array}$} & \multicolumn{2}{|c|}{$\begin{array}{l}\text { Inlet } \\
\text { pressure }\end{array}$} & \multicolumn{2}{|c|}{$\begin{array}{c}\text { Inlet } \\
\text { temperature }\end{array}$} & \multicolumn{2}{|c|}{$\begin{array}{l}\text { Reference } \\
\text { velocity }\end{array}$} & \multirow{2}{*}{$\begin{array}{l}\text { Simulated } \\
\text { compressor } \\
\text { pressure } \\
\text { ratio }\end{array}$} & \multirow[t]{2}{*}{ Comments } \\
\hline & $\mathrm{kg} / \mathrm{sec}$ & $\mathrm{lb} / \mathrm{sec}$ & $\mathrm{kPa}$ & psia & K & ${ }^{\circ} \mathrm{F}$ & $\mathrm{m} / \mathrm{sec}$ & $\mathrm{ft} / \mathrm{sec}$ & & \\
\hline $\begin{array}{l}A \\
B \\
C \\
D \\
E \\
F \\
G \\
H\end{array}$ & $\begin{array}{l}2.27 \\
3.05 \\
3.63 \\
1.23 \\
2.12 \\
1.83 \\
1.51 \\
1.23\end{array}$ & $\begin{array}{l}5 \\
6.71 \\
8 \\
2.70 \\
4.66 \\
4.02 \\
3.33 \\
2.70\end{array}$ & $\begin{array}{r}1014 \\
1358 \\
1620 \\
405 \\
862 \\
689 \\
517 \\
414\end{array}$ & $\begin{array}{c}147 \\
197 \\
235 \\
58.5 \\
125 \\
100 \\
75 \\
60\end{array}$ & $\begin{array}{l}686 \\
703 \\
717 \\
474 \\
627 \\
581 \\
526 \\
474\end{array}$ & $\begin{array}{l}775 \\
805 \\
830 \\
394 \\
668 \\
585 \\
486 \\
394\end{array}$ & $\begin{array}{l}5.5 \\
5.5 \\
5.5 \\
5.2 \\
5.5 \\
--- \\
--- \\
---\end{array}$ & $\begin{array}{l}18 \\
18 \\
18 \\
16.9 \\
18 \\
--- \\
--- \\
---\end{array}$ & $\begin{array}{l}10 \\
13.4 \\
16 \\
4 \\
8.5 \\
6.8 \\
5.1 \\
4.1\end{array}$ & $\begin{array}{l}\text { High-altitude cruise } \\
\text { Low-altitude cruise } \\
\text { Sea level take-off (SLTO) } \\
\text { Idle: f/a }=0.008 \\
\text { Simulated reduced power }\end{array}$ \\
\hline
\end{tabular}

aparametric variation based on increase in mass flow to provide increases of 33 and 66 percent in reference velocity. 


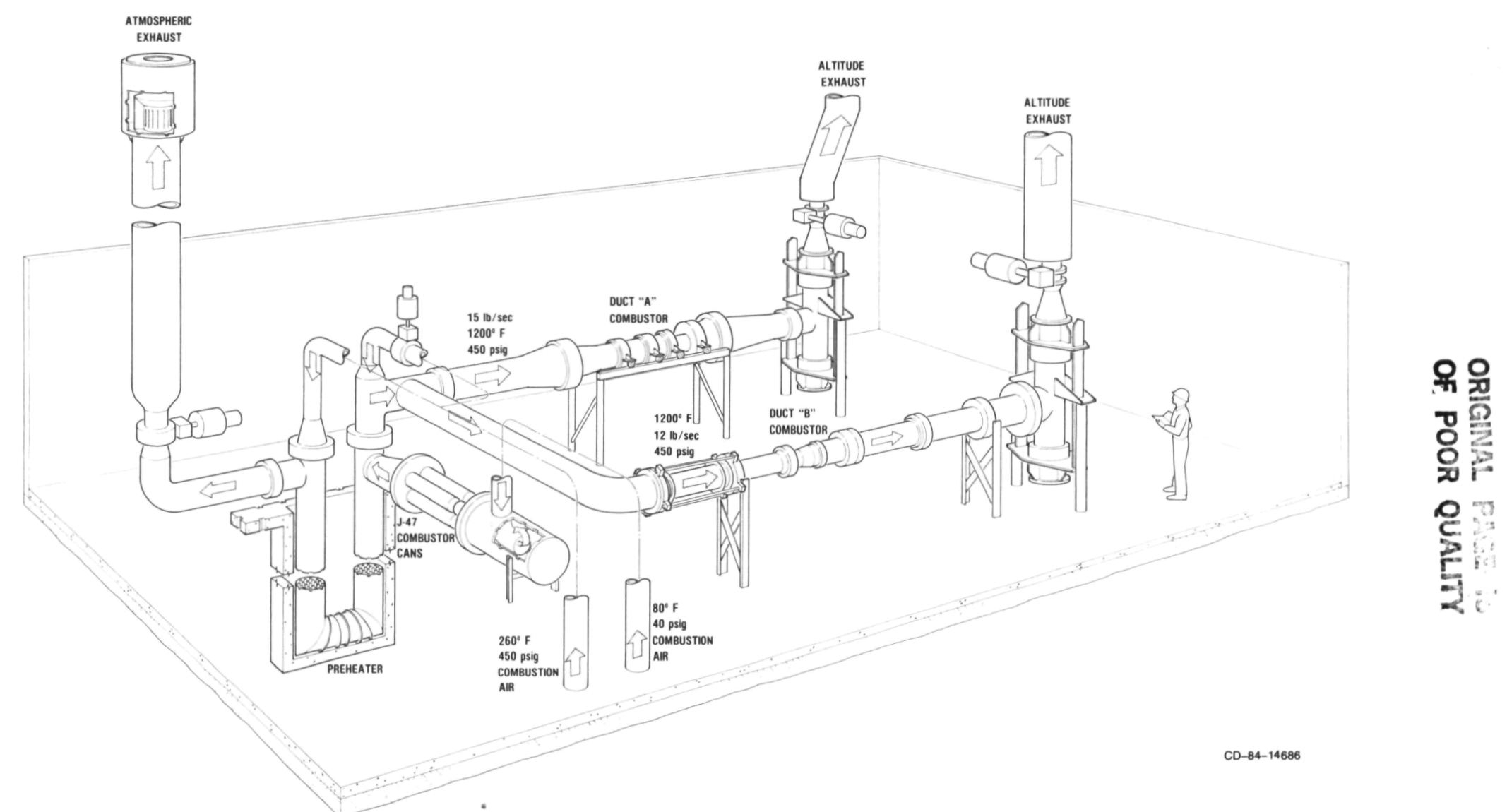

Figure $1_{\circ}$ - Sketch of closed-duct test facility. 
ORIGNAZ PROE

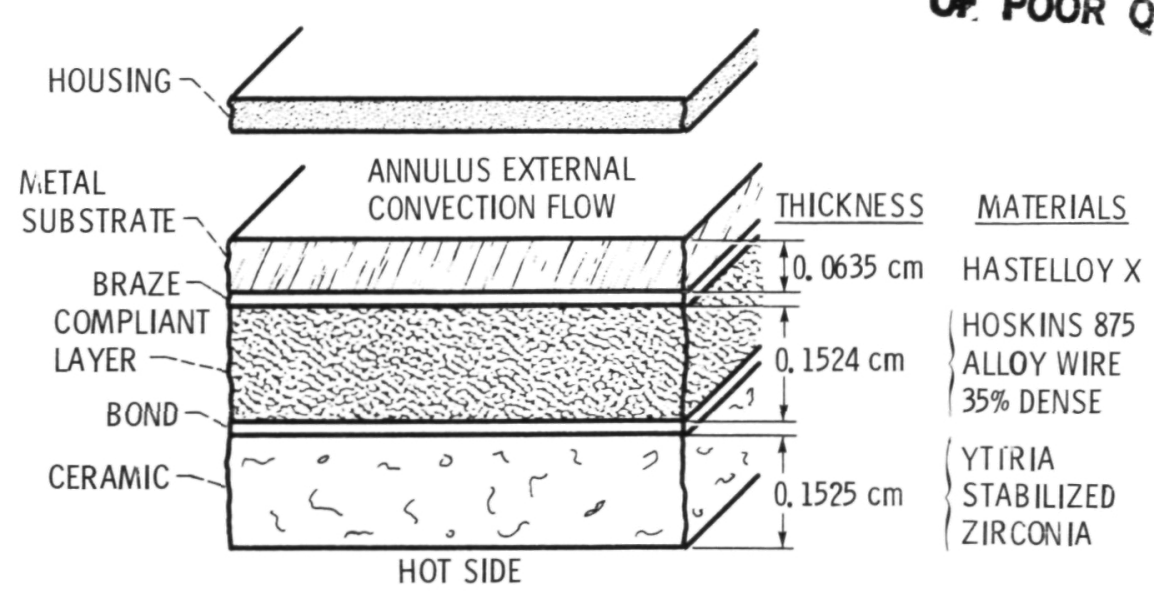

Figure 2. - Cross section of the compliant metal/ceramic liner concept. (not to scale)

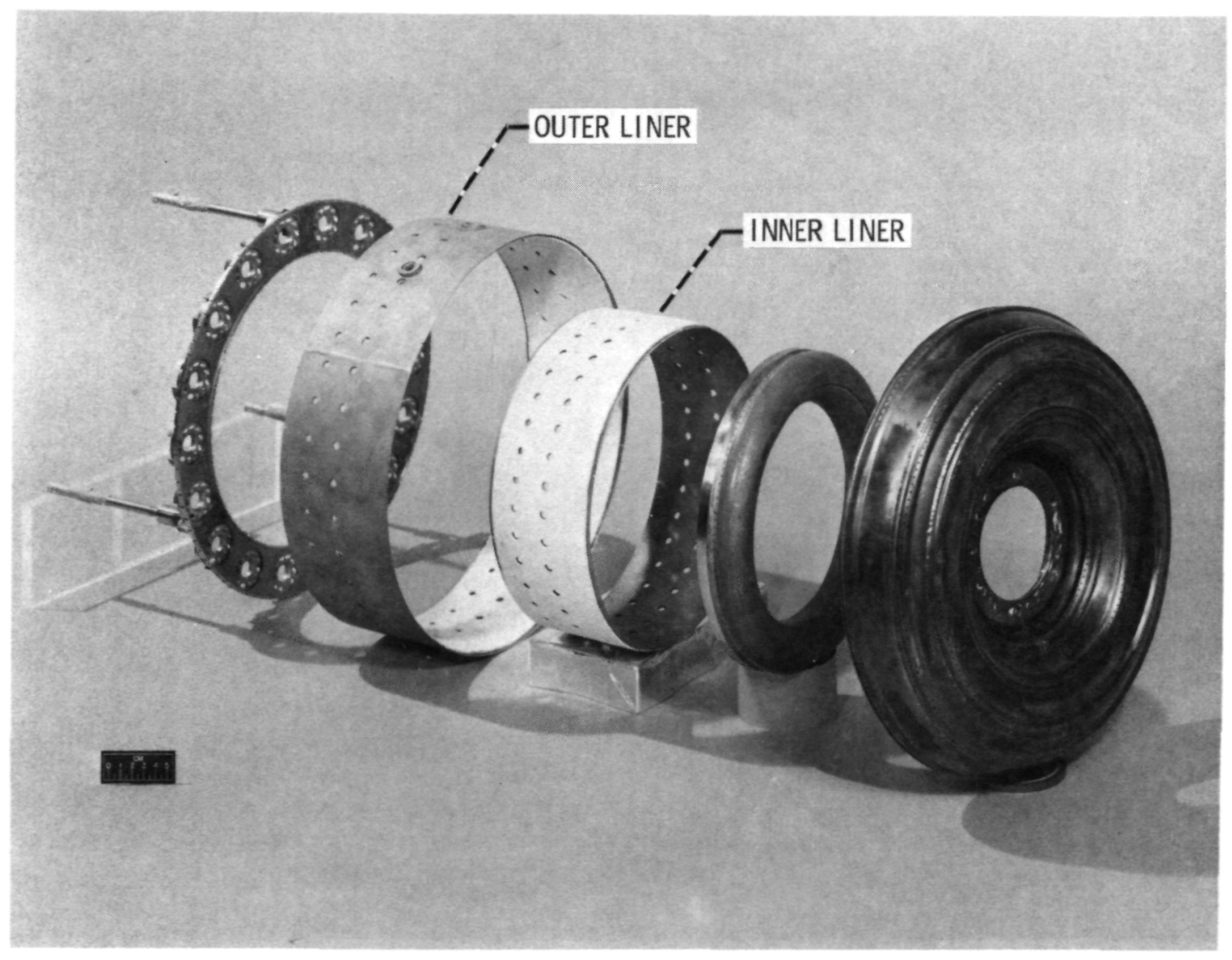

Figure 3. - Experimental combustor with compliant metal/ceramic liners. 

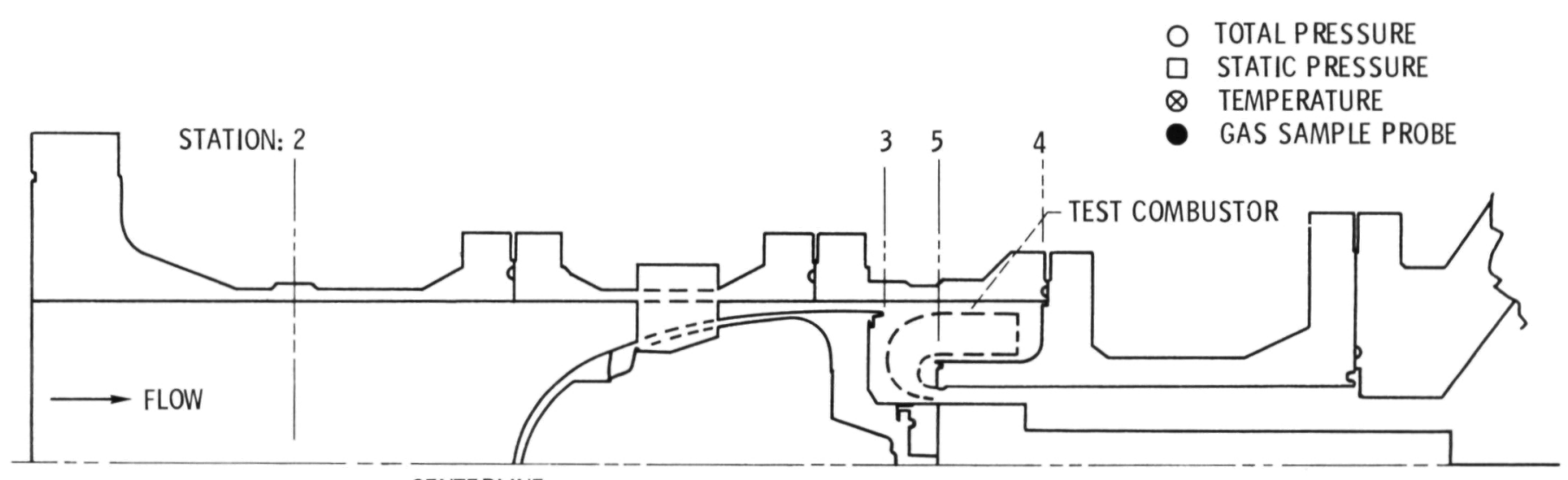

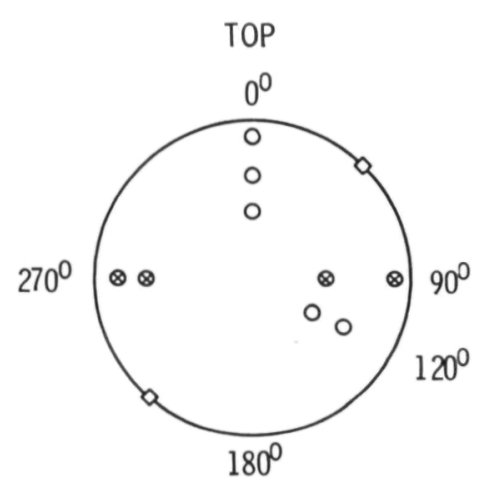

STATION 2 VIEWING UPSTREAM

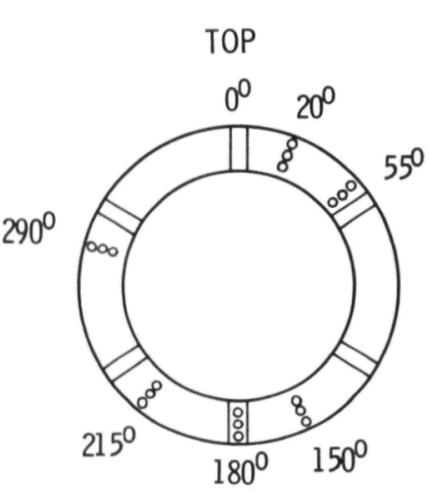

STATION 3

VIEWING UPSTREAM
COMBUSTOR

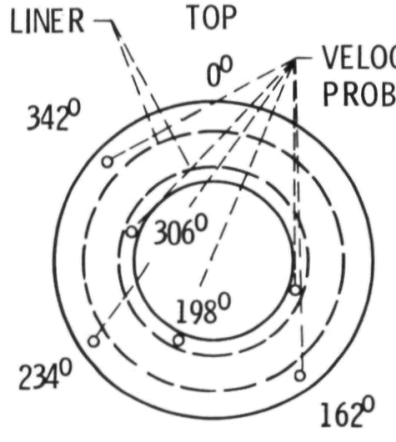

STATION 4

VIEWING UPSTREAM
ROTATING PROBE $360^{\circ}$

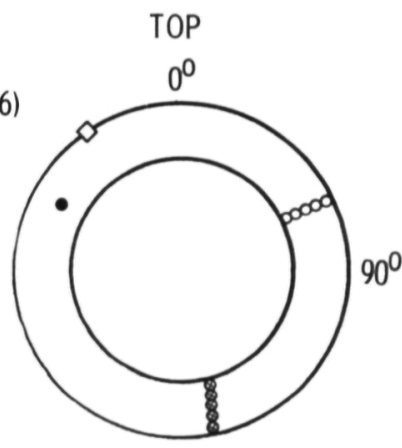

STATION 5 - COMBUSTOR EXIT VIEWING UPSTREAM

Figure 4. - Research instrumentation. 


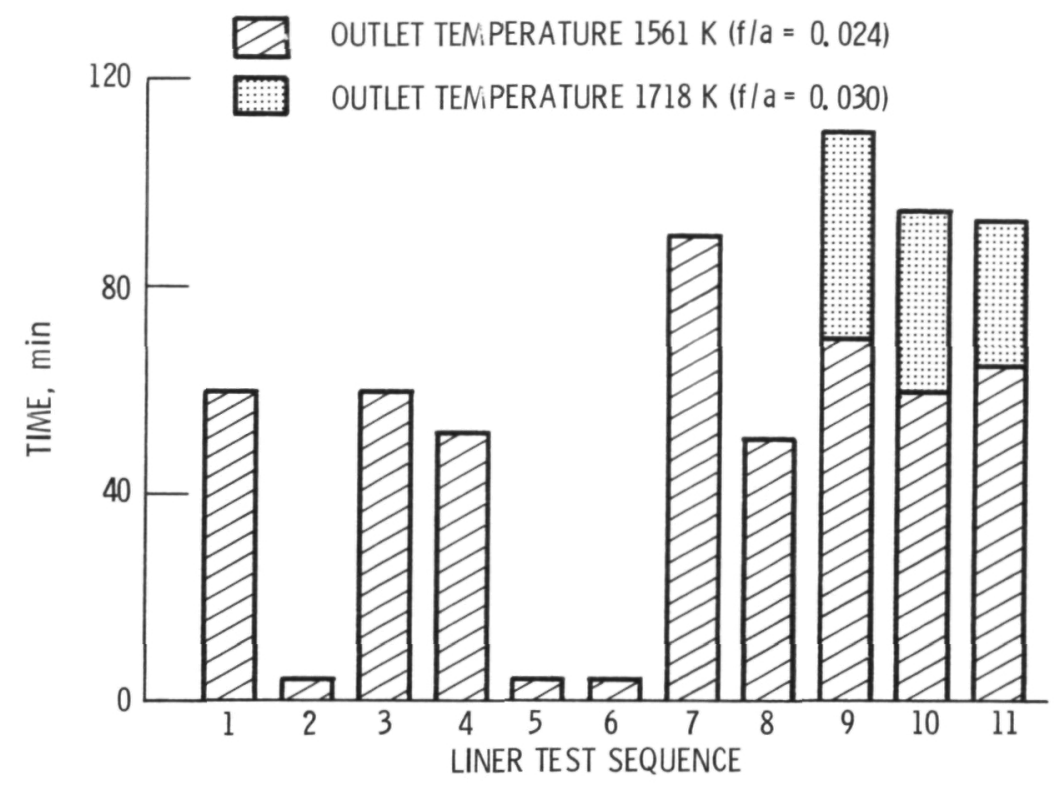

Figure 5. - Liner durability test sequence. Inlet pressure, $1620 \mathrm{kPa}$ (235 psia); inlet temperature, $717 \mathrm{~K}\left(830^{\circ} \mathrm{F}\right)$; total airflow, $3.63 \mathrm{~kg} / \mathrm{sec}(8 \mathrm{lb} / \mathrm{sec})$.

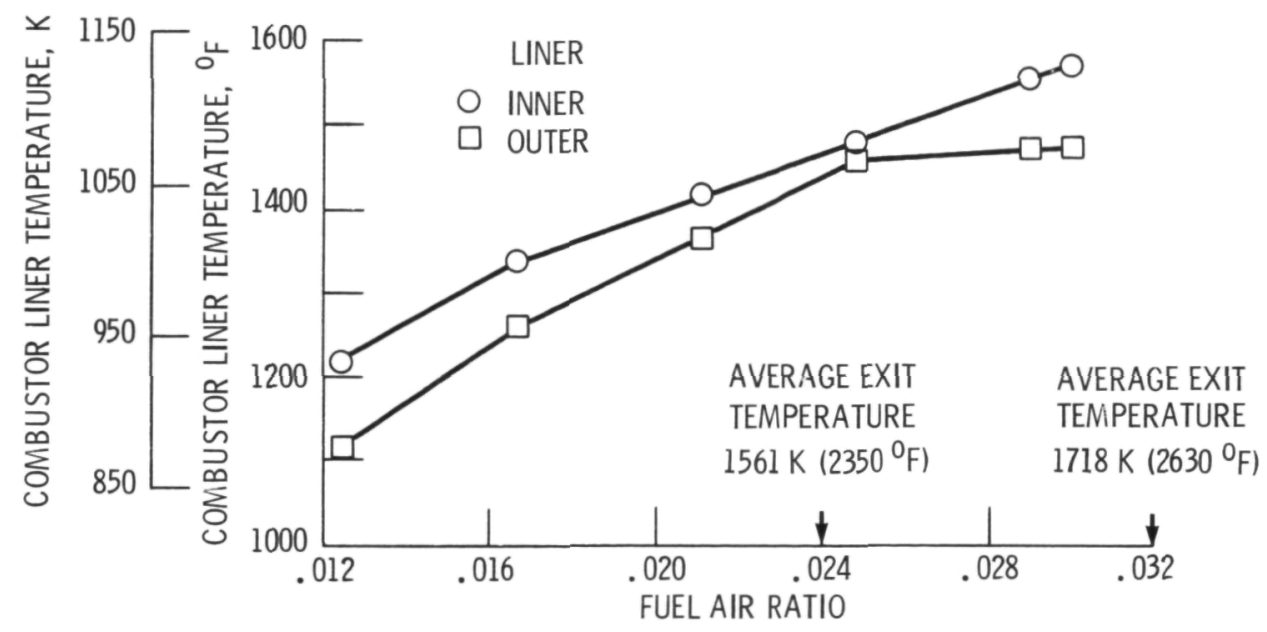

Figure 6. - Comparison of liner wall temperatures for the compliant metall ceramic liner. Inlet pressure, $1620 \mathrm{kPa}(235 \mathrm{psia})$; inlet temperature, $717 \mathrm{~K}\left(830^{\circ} \mathrm{F}\right)$; total airflow $3.63 \mathrm{~kg} / \mathrm{sec}(8 \mathrm{lb} / \mathrm{sec})$. 


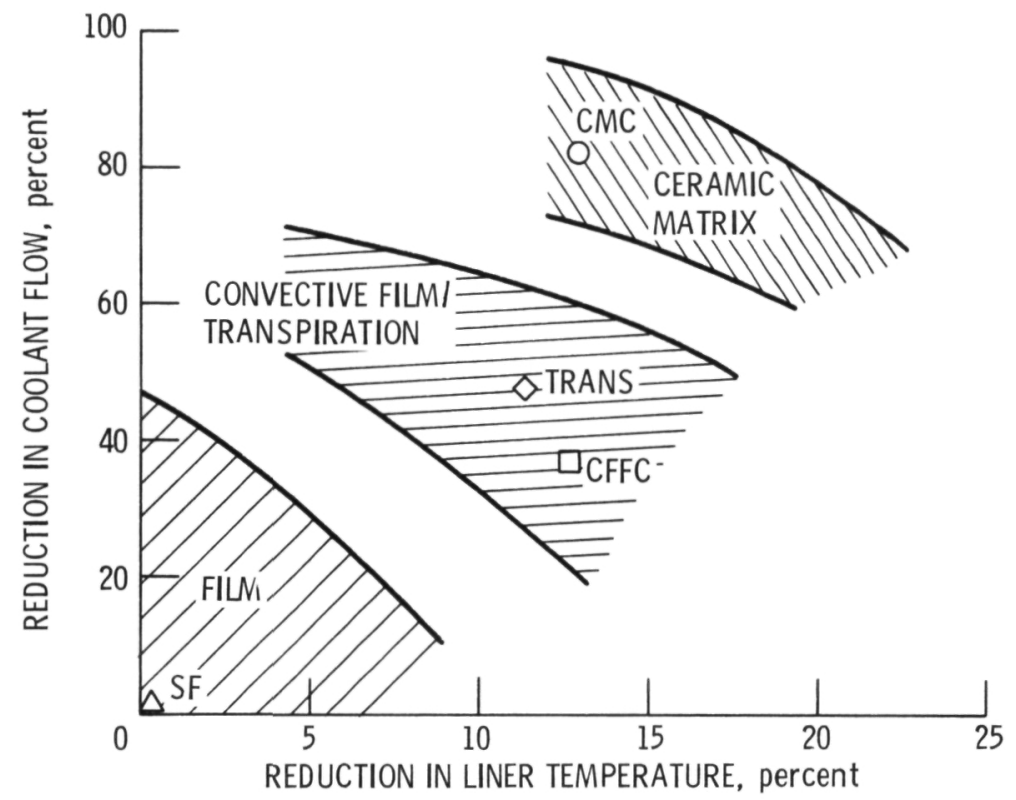

Figure 7. - Comparison of cooling effectiveness from a compliant metal/ceramic (CMC) liner with a counter-flow film-cooled (CFFC) liner, a Lamilloy (TRANS) liner, and a splash film (SF) liner. 


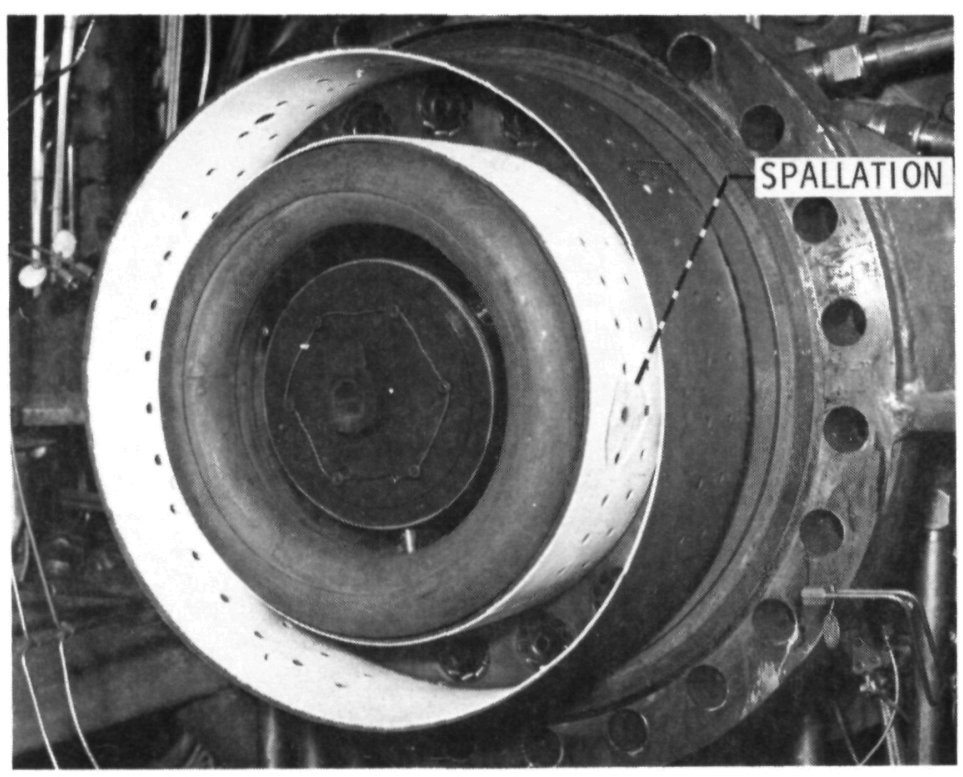

(a) Liner after first thermal cycle.

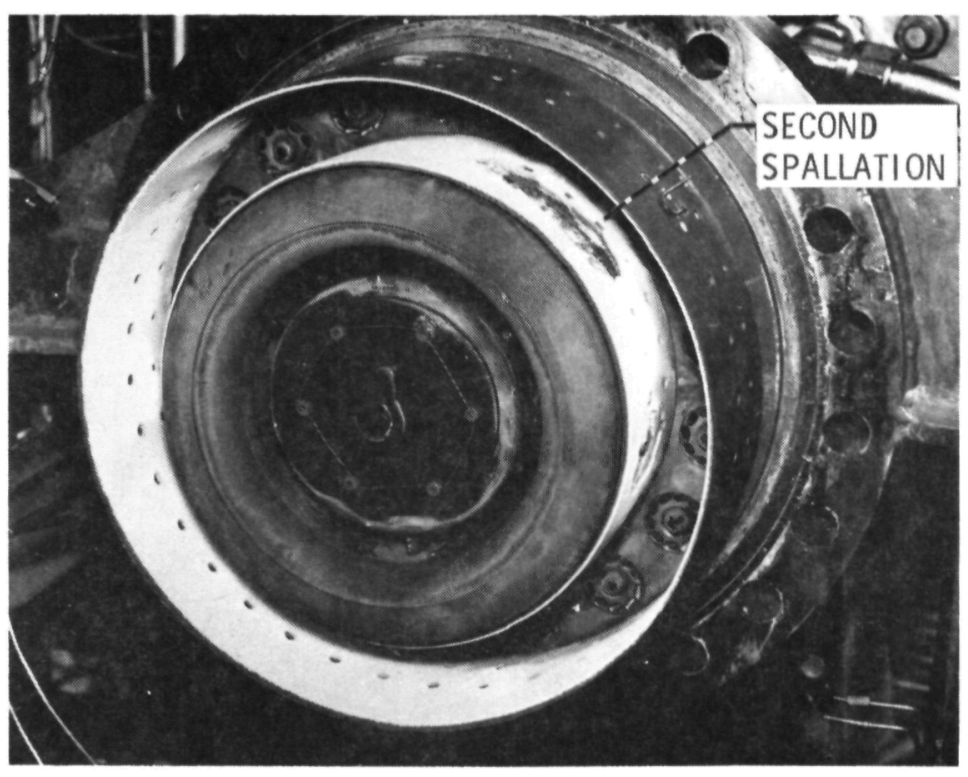

(b) Liner condition at conclusion of test.

Figure 8. - Liner condition after first ther mal cycle and at conclusion of test. 


\section{ORIGMAL PREE IS \\ OF POOR QUALITY}

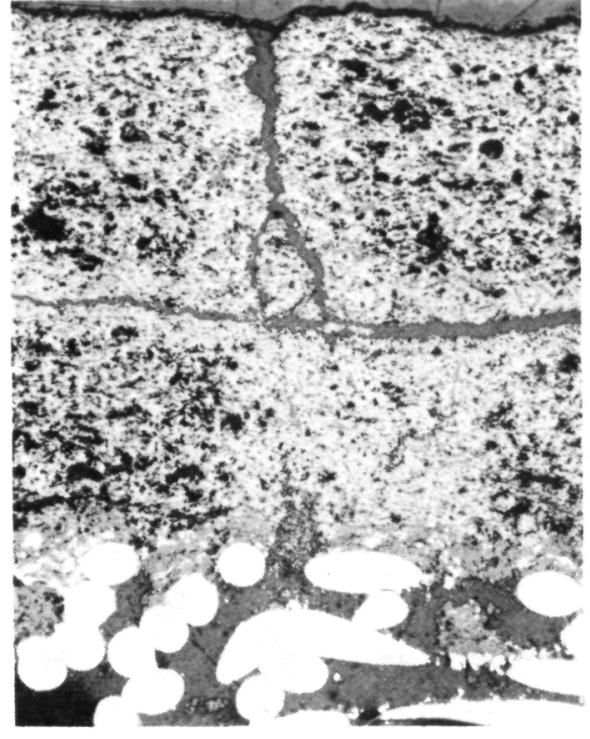

(a) Outer liner, 50X.

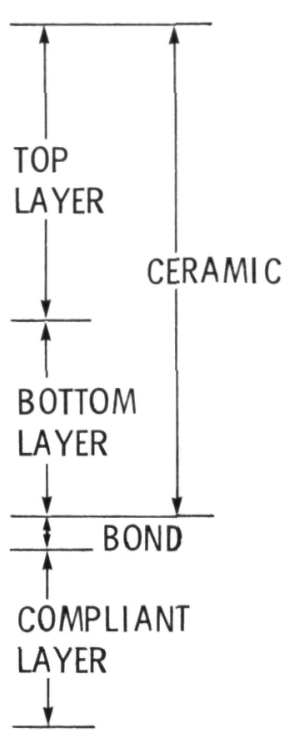

LAYER

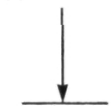

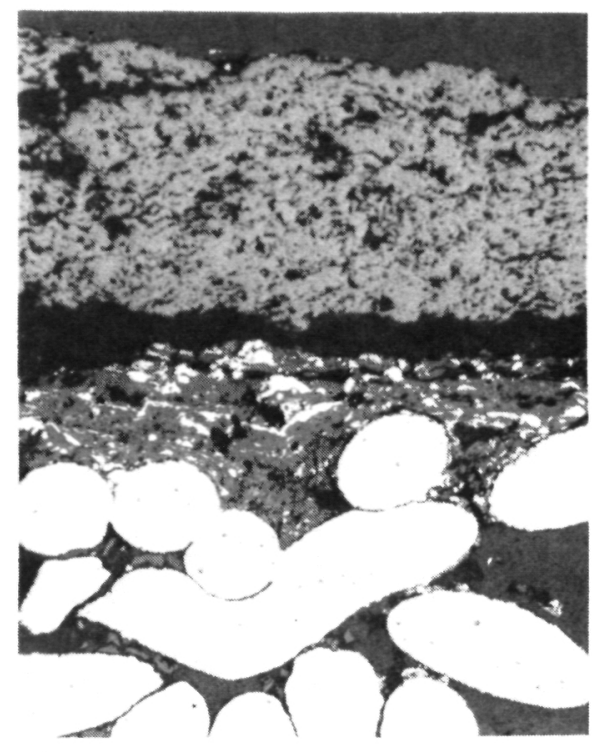

(b) Inner liner, 100x.

Figure 9. - Photomicrograph of liner cross sections.

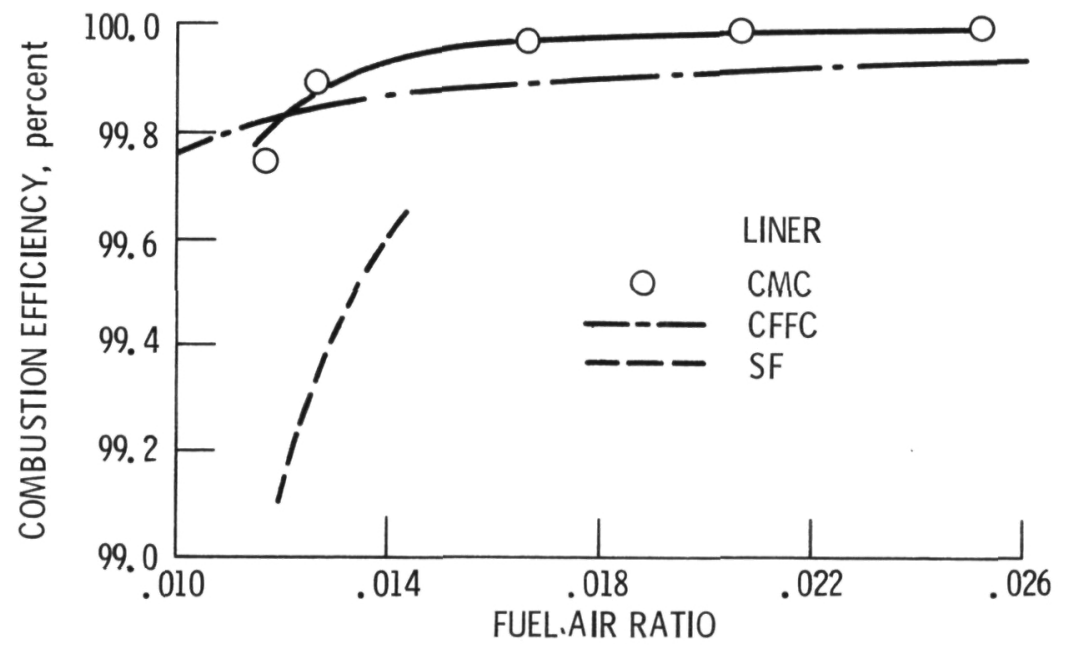

Figure 10. - Compliant metal/ceramic (CMC) combustor efficiency and comparison with splash-film (SF) and counterflow film-cooled (CFFC) configurations. Inlet pressure, $1620 \mathrm{kPa}(235 \mathrm{psia})$; inlet temperature, $717 \mathrm{~K}\left(830^{\circ} \mathrm{F}\right)$; total airflow, $3.63 \mathrm{~kg} / \mathrm{sec}(8 \mathrm{lb} / \mathrm{sec})$. 


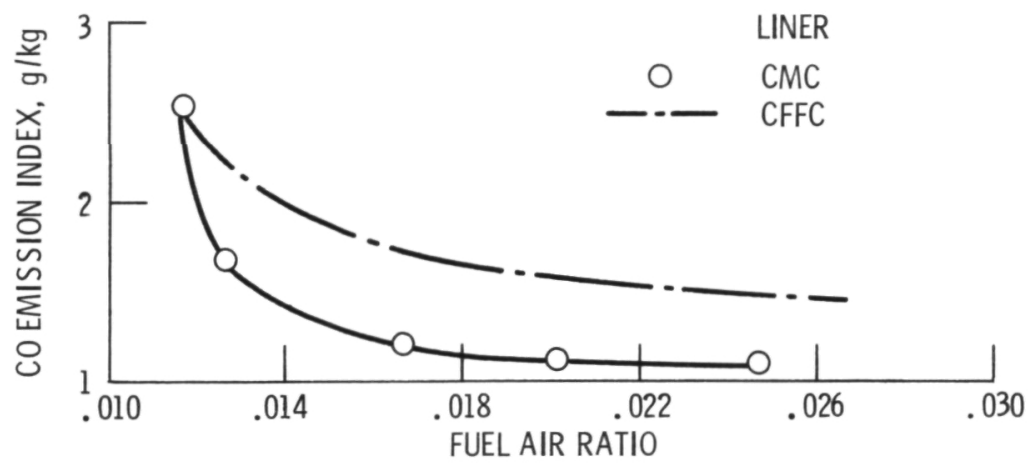

Figure 11. - Comparison of carbon monoxide emission from a compliant metal/ceramic (CMC) liner with a counter-flow film-cooled (CFFC) liner. Inlet pressure, $1620 \mathrm{kPa}(235 \mathrm{psia})$; inlet temperature, $717 \mathrm{~K}$ $\left(830^{\circ} \mathrm{F}\right)$; total airflow, $3.63 \mathrm{~kg} / \mathrm{sec}(8 \mathrm{lb} / \mathrm{sec})$.

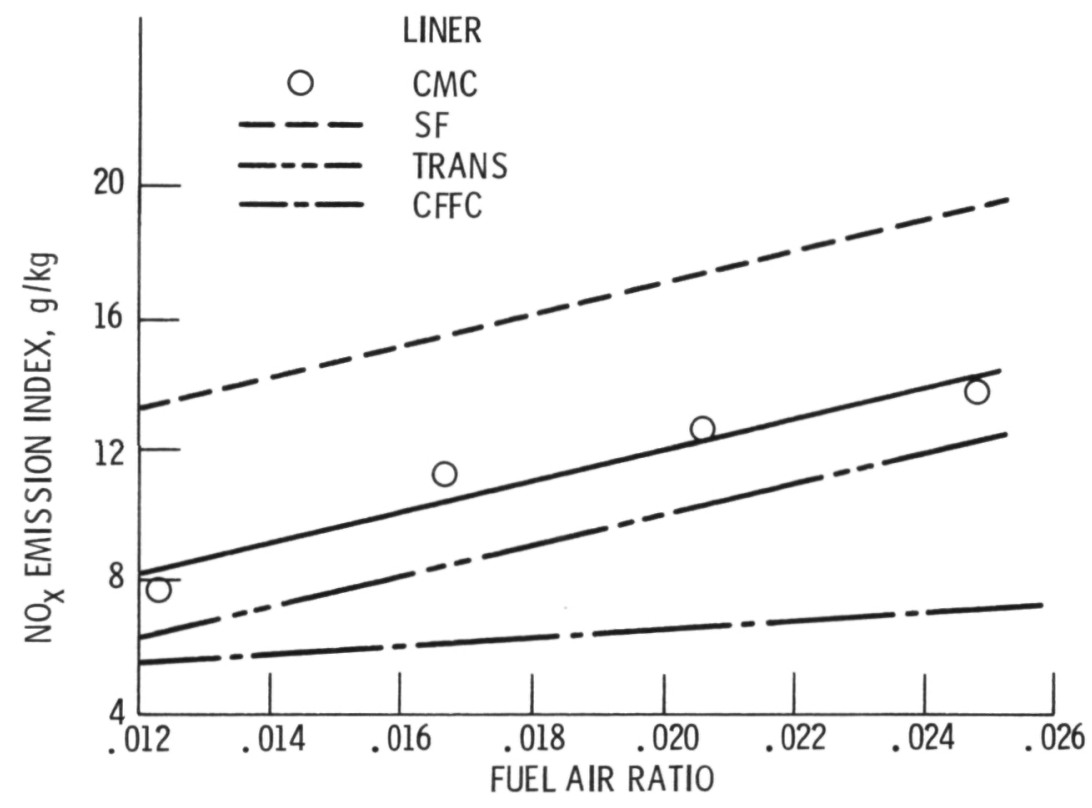

Figure 12. - Comparison of oxides of nitrogen emission from a compliant metal/ceramic (CMC) liner with a counter-flow filmcooled (CFFC) liner, a Lamilloy (TRANS) liner, and a splash film (SF) liner. Inlet pressure, $1620 \mathrm{kPa}(235 \mathrm{psia})$; inlet temperature, $717 \mathrm{~K}\left(830^{\circ} \mathrm{F}\right)$; total airflow, $3.63 \mathrm{~kg} / \mathrm{sec}(8 \mathrm{lb} / \mathrm{sec})$. 


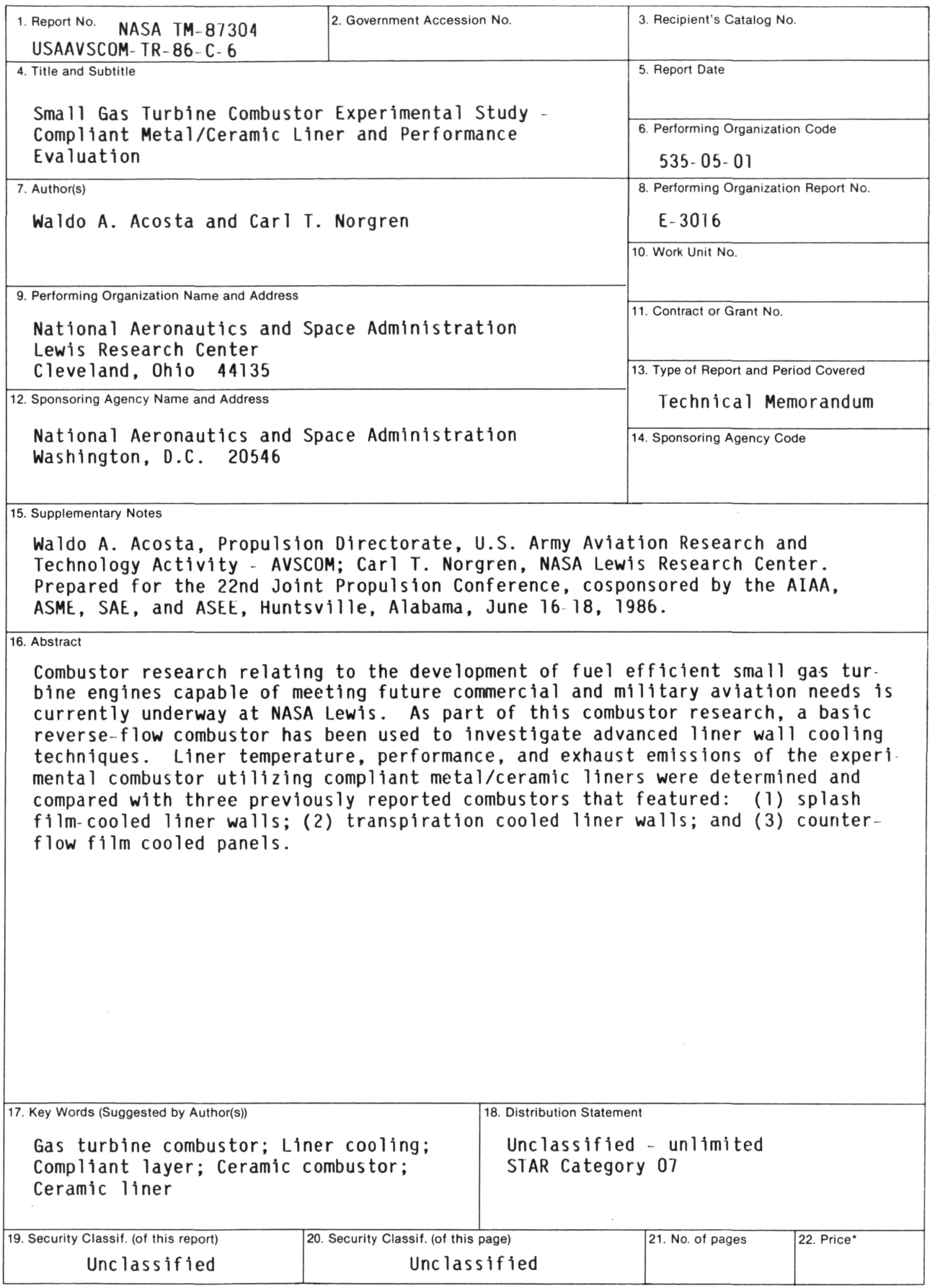

*For sale by the National Technical Information Service, Springfield, Virginia 22161 
National Aeronautics and

Space Administration

Lewis Research Center

Cleveland. Ohio 44135

Official Business

Penalty for Private Use $\$ 300$
SECOND CLASS MAIL

ADDRESS CORRECTION REQUESTED

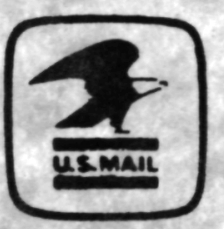

Postage and Fees Paid National Aeronautics and Space Administration NASA-451 